\title{
Intestinal Goblet Cells and Mucins in Health and Disease: Recent Insights and Progress
}

\author{
Young S. Kim • Samuel B. Ho
}

Published online: 13 August 2010

(C) The Author(s) 2010. This article is published with open access at Springerlink.com

\begin{abstract}
The mucus layer coating the gastrointestinal tract is the front line of innate host defense, largely because of the secretory products of intestinal goblet cells. Goblet cells synthesize secretory mucin glycoproteins (MUC2) and bioactive molecules such as epithelial membrane-bound mucins ( $M U C 1, M U C 3, M U C 17)$, trefoil factor peptides (TFF), resistin-like molecule $\beta$ (RELM $\beta)$, and Fc- $\gamma$ binding protein (Fcgbp). The MUC2 mucin protein forms trimers by disulfide bonding in cysteine-rich amino terminal von Willebrand factor (vWF) domains, coupled with crosslinking provided by TFF and Fegbp proteins with MUC2 vWF domains, resulting in a highly viscous extracellular layer. Colonization by commensal intestinal microbiota is limited to an outer "loose" mucus layer, and interacts with the diverse oligosaccharides of mucin glycoproteins, whereas an "inner" adherent mucus layer is largely devoid of bacteria. Defective mucus layers resulting from lack of $M U C 2$ mucin, mutated $M u c 2$ mucin vWF
\end{abstract}

\section{Y. S. Kim}

Genemed Biotechnologies,

458 Carlton Court,

South San Francisco, CA 94080, USA

Y. S. Kim

GI Section (111B), Veterans Affairs Medical Center,

San Francisco, CA, USA

\section{Y. S. Kim $(\bowtie)$}

Department of Medicine, University of California,

San Francisco, CA 94121, USA

e-mail: young.kim@ucsf.edu

\section{S. B. Ho}

Gastroenterology (111D), VA San Diego Healthcare System, 3350 La Jolla Village Drive,

San Diego, CA 92161, USA

e-mail: samuel.ho2@va.gov domains, or from deletion of core mucin glycosyltransferase enzymes in mice result in increased bacterial adhesion to the surface epithelium, increased intestinal permeability, and enhanced susceptibility to colitis caused by dextran sodium sulfate. Changes in mucin gene expression and mucin glycan structures occur in cancers of the intestine, contributing to diverse biologic properties involved in the development and progression of cancer. Further research is needed on identification and functional significance of various components of mucus layers and the complex interactions among mucus layers, microbiota, epithelial cells, and the underlying innate and adaptive immunity. Further elucidation of the regulatory mechanisms involved in mucin changes in cancer and inflammation may lead to the development of novel therapeutic approaches.

Keywords Intestinal goblet cell · Mucin - Glycan .

Mucus barrier - Microbiota - Parasites · Intestinal infections . Cystic fibrosis - Inflammatory bowel disease .

Mucinous adenocarcinoma $\cdot$ Colorectal cancer

\section{Introduction}

The intestine plays an important role in the digestion and absorption of ingested food and the elimination of undigested food, microbes, and microbial products. The functional integrity of the intestinal mucosal epithelial cells depends on the coordinated regulation of the mucus layer, the intercellular tight junction, epithelial cells, and host innate and adaptive immune response [1, 2•]. The mucus layer overlying the epithelium secreted by the goblet cells promotes the elimination of gut contents and provides the first line of defense against physical and chemical injury caused by ingested food, microbes and the microbial 
products. The major component of the mucus is secreted mucins, large glycoproteins with highly polymeric protein backbone structure, linked to numerous hygroscopic and hydrophilic oligosaccharide side-chains that contribute to the formation of gel-like structure [3, 4]. Intestine is the major site of bacterial colonization, with more than 1000 prevalent bacterial species identified. These commensal bacteria are trapped in the mucus layer, failing to reach the epithelial cell surface, and are eliminated by peristaltic movement $[1,2 \cdot]$. The microbes and microbial products are recognized by the sensor system of the intestinal epithelial cells and the immune cells, activating the host innate defense system. Balanced and dynamic interactions among mucus layers, intestinal epithelial cells, microbiota, and host immune defense is essential for the maintenance of the intestinal mucosal homeostasis. The disruption in the intestinal homeostasis results in the defective mucus barrier with increased permeability that results in inflammation and injury of the intestinal mucosal cells $[1,5 \cdot]$. This review briefly summarizes the recent progress made in understanding of the regulation of goblet cell differentiation and biology, the delineation of mucus layers in the intestine, structure, gene family, regulation and biology of mucins, interaction of mucins and microbiota in intestinal ecosystem, and the role of goblet cells and mucins in intestinal disorders such as intestinal infections, inflammatory bowel disease (IBD), and cystic fibrosis $(\mathrm{CF})$, and mucinous adenocarcinoma.

\section{Goblet Cells: Differentiation and Biology}

The intestinal mucosal epithelium consists of four main cell types-absorptive enterocytes, goblet cells, Paneth cells, and enteroendocrine cells - which undergo continuous cycles of renewal. The small intestinal epithelium is divided into two distinct compartments. The lower crypt compartment consists of pluripotent stem cells residing at the bottom of the crypt, recently identified by the stem cell marker Lgr5, and proliferating transit amplifying cells that differentiate into mature cell lineages (absorptive, goblet, and enteroendocrine cells) during migration toward the villus compartment. Paneth cells settle and undergo differentiation at the crypt bottoms [6•]. Goblet cells appear early in development (in the human fetal small intestine, at 9-10 weeks' gestation) and relatively undifferentiated oligomucous and mature goblet cells are present in both the stratified and simple columnar epithelium; however, once the villi have formed, most goblet cells are indistinguishable from those found in the adult intestine. The goblet cell morphology is shaped by the distended theca containing the mucin granules located below the apical membrane. In mice deficient in the major goblet cell mucin, Muc2 $\left(\mathrm{Muc2}^{-\alpha}\right)$, no morphologically identifiable goblet cells can be identified as the theca collapse, despite the continued presence of other goblet cell products, such as intestinal trefoil factor (TFF3) [7]. By contrast, in mice deficient in TFF3 $\left(\mathrm{TFF}^{-/}\right)$, goblet cells can be identified despite smaller theca, indicating the predominant role of mucin in goblet cell morphology [8]. The proportion of goblet cells among epithelial cell types increases caudally from duodenum $(4 \%)$ to distal colon $(16 \%)$, similar to the increasing number of microbial organisms present in the proximal intestine to colon [9]. There are fewer and smaller goblet cells in the intestine of the germ-free mice compared to those of conventionally raised mice, indicating the microbial modulation of goblet cells [10].

The maintenance of stem cells and differentiation into specific cell lineages in the intestine involves complex interplay of multiple developmental pathways including Wnt $/ \beta$-catenin, bone morphogenic protein (BMP), and PI3kinase/Akt signaling [6•]. Notch signaling pathway plays a central role in cell fate specification and differentiation in the intestine $[6,11]$. Notch signaling results in the activation of Hes1 transcription factor, which has a repressive effect on bHLH transcription factor Math1 (the human homologue is Hath1). Inhibition of Notch pathway in the intestinal epithelium results in a rapid and complete conversion of all epithelial cells to secretory cell lineage cells such as goblet, Paneth, and enteroendocrine cells concomitant with activation of Math1; whereas activation of Notch signaling pathway leads to depletion of all secretory cells with the villi lined mainly with absorptive enterocytes concomitant with activation of Hes1 [6, 11]. Hath1 was previously shown to be essential for differentiation of intestinal secretory lineage cells. Activation of Hath1 caused induction of MUC2, a major goblet cell mucin, by binding to its binding sites, Eboxes on $M U C 2$ promoter $[12,13]$. In addition, activation of transcription factors, Klf4 and Elf3, is involved in the terminal differentiation of goblet cells $[6 \bullet]$.

Goblet cells synthesize and secrete bioactive molecules such as secretory and membrane-bound mucins, trefoil peptides, resistin-like molecule $\beta$ (RELM $\beta)$, and $\mathrm{Fc}-\gamma$ binding protein (Fcgbp), which are components of mucus [2•]. These molecules are secreted by two pathways, constitutive or basal secretion, which is low-level continuous secretion dependent on cytoskeletal movement of secretory granules, or stimulated or regulated secretion, which involves exocytosis of granules in response to external stimuli [14].

\section{Mucins: Main Goblet Cell Product}

\section{Structure and Classification of Mucins}

Mucins are highly glycosylated large glycoproteins with protein backbone structures rich in serine and threonine, which are linked to a wide variety of O-linked oligosaccharide 
side chains that make up more than $70 \%$ of the weight of the molecule $[3,4]$. Up to 20 different mucin genes have been identified, $M U C 1$ to $M U C 20$ according to order of their discovery. Mucin genes are expressed in tissue and cell typespecific manner and are broadly classified into two types, secretory and membrane-associated. Gel-forming secretory mucins such as MUC2, MUC5AC, MUC5B, and MUC6 are localized on chromosome 11.5.5 as a cluster. In small and large intestine, $M U C 2$ is the major secretory mucin synthesized and secreted by goblet cells, whereas goblet and absorptive cells express membrane-bound mucins, MUC1, MUC3, MUC4, MUC13, and/or MUC17, in the apical membrane $[3,4,15]$. Secretory and membrane mucins have distinct structural features and biosynthetic pathways.

$M U C 2$ is the first human secretory mucin to be identified and characterized $[15,16]$. MUC2 mucin has structural and physicochemical properties similar to those of other gelforming secretory mucin such as $M U C 5 A C, M U C 5 B$, and $M U C 6$, expressed in gastric and respiratory glandular epithelium. MUC2 mucin monomer has more than 5000 amino acids and consists of central tandem repeat domains rich in proline, serine, and threonine, the latter of which are linked O-glycosidically to many oligosaccharide side chains of varying lengths and compositions (also called "PTS" domains). The highly glycosylated central tandem repeat domains of $M U C 2$ mucin monomers are flanked on either side by the cysteine-rich domains, including Cterminal cysteine knot domain and four D domains of von Willebrand factor (vWF), which are involved in dimerization and oligomerization, respectively, resulting in highly viscous gel-forming mucin network (Fig. 1) [16-18]. The rodent homologue of $M U C 2$ is designated as $M u c 2$, and has a similar structure motif and cell and tissue type-specific expression.

Intestinal mucosal epithelia cells also express epithelial membrane-bound mucins, $M U C 1, M U C 3, M U C 4, M U C 12$, $M U C 13$, and MUC17, which have structural similarity. MUC3 mucin, the most abundantly expressed membrane mucin in the small intestine, consists of two subunits, an extracellular subunit containing heavily O-glycosylated tandem repeat domains and two epidermal growth factor (EGF) - like domains separated by sperm protein, enterokinase, and agrin (SEA) module, a proteolytic cleavage site during biosynthesis of $M U C 3$ in the endoplasmic reticulum, and a membrane-associated subunit with trans-membrane domain and cytoplasmic tail with potential phosphorylation sites involved in signaling (Fig. 1) [19-21]. MUC3 expression in the apical membrane of absorptive and goblet cells shows a maturational gradient with increasing expression from crypt to villus. These membrane mucins extend rod-like 200-1500 $\mathrm{nm}$ above the cell surface and form the glycocalyx (Fig. 1). The membrane mucins may be shed from the cell surface by the activation of membrane- associated metalloproteinases, by the separation of two subunits in the SEA domain, or by the alternative splicing contributing to mucus layer formation [3]. The cysteine-rich EGF-like domains of the mouse $M u c 3$ and human $M U C 17$ mucins have been shown to inhibit apoptosis and stimulate cell migration, implying a bioactive role in maintaining the integrity of the surface epithelial layer [22, 23].

\section{Biosynthesis and Secretion of Mucins}

Like other gel-forming secretory mucins, MUC2 mucin monomers form dimers in the endoplasmic reticulum via intermolecular disulfide bonding between the c-terminal cysteine knot domains. During transit through Golgi apparatus, $M U C 2$ mucin proteins become heavily O-glycosylated and undergo trimerization via disulfide bonding in the amino terminal region, resulting in the formation of very large polymers $[17,18]$. Proteolytic processing may also occur in the late secretory compartments. It is possible that other mucin proteins, such as $M U C 5 B$, may polymerize with a different pattern, forming linear chains rather than trimers at the amino terminal region as with $M U C 2$ [24]. Numerous and diverse oligosaccharide side chains linked Oglycosidically to apomucin are synthesized by the sequential addition of five different sugars by the action of a series of Golgi resident glycosyltransferases. These oligosaccharides can generate diverse signals by binding to many different ligands such as bacteria, viruses, lectins, adhesion molecules, growth factors, and cytokines [25, 26*]. The glycosylated MUC2 monomer has a mass of about $2.5 \mathrm{MDa}$ and the polymer may be more than $100 \mathrm{MDa}$. The fully glycosylated and processed $M U C 2$ mucin is densely packed and stored in secretory granules/vesicles and released by two pathways, constitutive/basal and $\mathrm{Ca}^{+}$-dependent stimulated/regulated pathways described in the previous section. Massive secretion of $M U C 2$ mucin by exocytosis in stimulated secretion is triggered by a wide array of bioactive factors, including cholinergic agonist, hormones (neuropeptides), microbes and microbial products and toxins, inflammatory cytokines, and reactive oxygen and nitrogen species. These mucin secretagogues signal through secondary messengers such as intracellular $\mathrm{Ca}^{2+}$, cyclic adenosine monophosphate (cAMP), and diacylglycerol that activates protein kinase [14].

\section{Regulation of Mucin Synthesis}

Mucin secretion is frequently coupled with increased synthesis of mucins, but chronic secretion may result in goblet cell depletion and decreased synthesis of mucins. The syntheses of mucins are regulated by many bioactive factors that function as mucin secretagogues. Increasing evidence indicate that mucin expression is controlled either by transcriptional or epigenetic regulation $[4,27,28]$. Transcriptional regulation of 

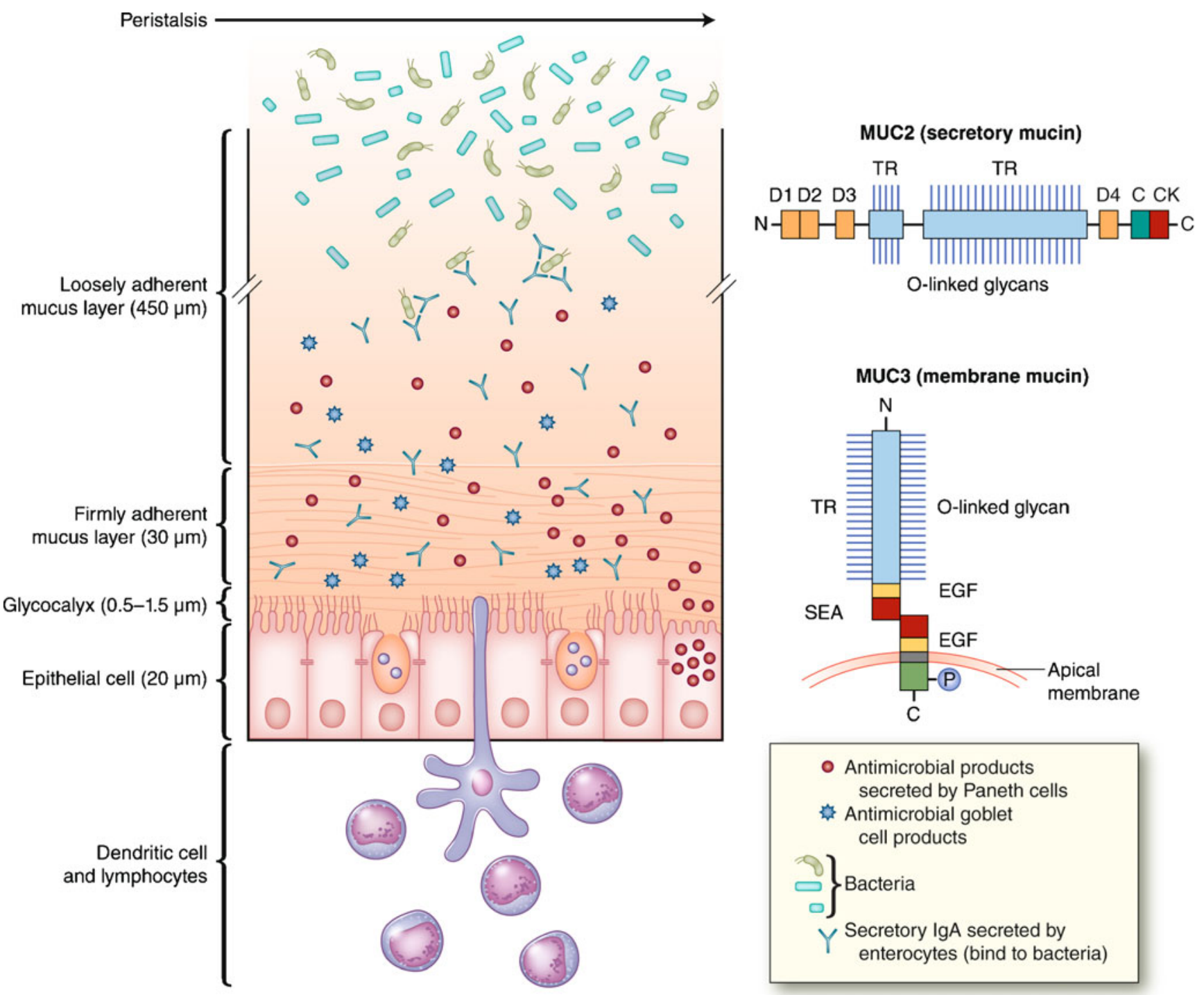

Fig. 1 A schematic representation of two mucus layers overlying the epithelial cell surface shown (left) and the domain structures of secretory (MUC2) and membrane-bound (MUC3) mucins shown (right). Intestinal epithelial cell surface is covered by two mucus layers (inner, firmly adherent layer and outer, loosely adherent layer) consisting largely of MUC2 mucin network produced by the goblet cells and other host defense molecules produced by goblet cells, Paneth cells, and absorptive enterocytes. Microbes are associated with the outer, loosely adherent mucus layer, but are absent in the inner, firmly adherent mucus layer. Epithelial cell surface is covered by glycocalyx, which consists of membrane-bound mucins (MUC3 and $M U C 17$ in the small intestine) and other membrane glycoproteins. The measurements shown are for the rat ileum. The domain structure of

MUC2 is mediated by activation of signaling pathways targeting the transcription factors that bind to specific sites on $M U C 2$ promoter. Bioactive factors including microbes, microbial products, toxins, cytokines, hormones/neuropeptides, and growth factors have been reported to be involved in positive or negative regulation of $M U C 2$ transcription [4, 28]. Activation of a transcription factor, nuclear factor (NF)-
MUC2 monomer shows central tandem repeat (TR) regions rich in proline, threonine, and serine (PTS domain), to which many oligosaccharide side chains (O-linked glycan) are linked, and four von Willebrand factor D domains flanking the tandem repeat (PTS) domains and C-terminal cysteine knot (CK) domain, which is involved in initial MUC2 dimerization. The domain structure of MUC3 mucin shows that it consists of two subunits, one extracellular and one membrane-bound. The extracellular subunit consists of a glycosylated tandem repeat (PTS) domain and two epidermal growth factor (EGF) - like domains separated by sperm protein, enterokinase, and agrin (SEA) motif (a proteolytic cleavage site during biosynthesis) and a membrane-bound subunit that consist of membrane-spanning domain and a cytoplasmic tail with potential phosphorylation $(\mathrm{P})$ sites

$\mathrm{KB}$, is a common event during inflammation in the gastrointestinal tract and $M U C 2$ mucin has been shown to have NF-KB binding sites in the promoter. Lipopolysaccharide (LPS) from gram-negative Pseudomonas aeruginosa upregulates $M U C 2$ transcription through activation of NF$\mathrm{KB}$ mediated by the Ras-mitogen-activated protein kinase (MAPK) pathway in colon epithelial cells. P. aeruginosa 
also binds to a glycolipid receptor, asialo GM1, at the cell surface through flagellin, causing the release of adenosine triphosphate (ATP), which in turn increases the intracellular $\mathrm{Ca}^{2+}$ concentration, leading to the activation of NF- $\mathrm{kB}$ mediated by downstream signaling pathways [29]. An inflammatory cytokine, tumor necrosis factor (TNF)- $\alpha$ (Th1 type cytokine), upregulates $M U C 2$ transcription through activation of NF-kB mediated by PI3K/Akt pathways. TNF- $\alpha$ also has an inhibitory effect on MUC2 transcription through activation of JNK pathway, but overall effect of TNF- $\alpha$ treatment of colon cancer cells is a net increase in MUC2 transcription [30]. Th2 type cytokines, interleukin (IL)-4 and IL-13, also upregulate MUC2 transcription through NF- $\mathrm{KB}$ activation mediated by MAPK [31]. By contrast, a neuropeptide hormone, vasoactive intestinal peptide (VIP), upregulates $M U C 2$ transcription through activation of transcription factors CREB/ATF1 mediated by MAPK and $\mathrm{p} 38$ pathways [32]. A prostaglandin, PGE2, also induced $M U C 2$ transcription through activation of CREB/ATF1. To summarize, both Th1 and Th2 cytokines and microbial products, LPS, lipoteichoic acid (LTA), lipopeptide (LP), and flagellin induce $M U C 2$ transcription through activation of NF- $\mathrm{BB}$, whereas activation of CREB/ATF1 is involved in neuropeptide/hormoneinduced MUC2 transcription. Recently, the SPDEF (SAM pointed domain-containing Ets) transcription factor has been shown to work downstream of Math1 to promote differentiation of secretory progenitor cells into goblet and Paneth cells, and is a major regulator of secretory gene products such as MUC2 [33].

Epigenetics describes heritable changes in gene expression that are not associated with changes in genomic DNA sequences. Epigenetic regulation that leads to the turning on or off of genes involves close interaction of DNA methylation, histone modifications, and microRNA silencing. Studies of $M U C 2$ in mucinous and nonmucinous colon cancers showed that methylation of $\mathrm{CpG}$ islands in the specific regions of $M U C 2$ promoter downregulates $M U C 2$ expression [34]. A recent study also showed that $M U C 2$ gene expression is regulated by a tightly associated epigenetic mechanisms of DNA methylation and histone modifications in the $5^{\prime}$ flanking region of $M U C 2$ promoter [35].

\section{Intestinal Mucus Layer and Commensal Microbes}

\section{Intestinal Mucus Layer}

Intestinal mucus layers secreted by goblet cells consist mainly of compact mesh-like network of viscous, permeable, gelforming MUC2 mucin, which provides the frontline host defense against endogenous and exogenous irritants and microbial attachment and invasion but allows the transport of nutrients. Mucus layers also contain other goblet cell products, TFF3, RELM $\beta$, and Fcgbp; antimicrobials peptides such as $\beta$ defensin and lysozymes secreted by Paneth cells; and secretory $\operatorname{IgA}$ secreted by enterocytes $[1,2,5,10]$. There are two mucus gel layers in the gastrointestinal mucosa, an inner firmly adherent layer and an outer more loosely adherent layer, both consisting largely of $M U C 2$ mucin in the intestine (Fig. 1) [36, 37]. Gastric mucus in the human stomach consists of MUC5AC and MUC6 mucins [38, 39]. A study of the thickness of two mucus layers in the rat gastrointestinal mucosa showed that the inner firmly adherent layer was much thicker and continuous in stomach, ileum, and colon compared to jejunum, which had a much thinner, patchy inner mucus layer (Table 1) [36]. Microfold (M) cells in the intestinal mucosal epithelium are devoid of overlying mucus layers and have the ability for transepithelial transport of foreign antigens and microbes to be captured by the underlying dendritic cells [40]. The outer loosely adherent mucus layer formed by proteolytic and glycosidic degradation of highly polymerized gel-like $M U C 2$ mucin was similar in thickness in stomach and jejunum, but markedly increased in ileum, and thickest in colon (Table 1) [36]. Microbes are associated mostly in the outer loose mucus layer and absent from the inner firm mucus layer, indicating that the inner firm mucus layer functions as a critical protective barrier against bacterial adhesion and invasion of underlying epithelial cells $[41 \bullet \bullet]$. The outer loose mucus layer provides a good habitat for microbial colonization, because oligosaccharides of $M U C 2$ mucin provide numerous microbial attachment sites and energy source (Fig. 1) [42••]. Muc2-deficient mice lack the intestinal mucus layers and demonstrate increased permeability and bacterial adherence to the epithelial cell surface $[41,43]$. The thickness of mucus layers is maintained by a balance between synthesis, secretion, and degradation, modulated by the microbial glycosidases and proteases and the mechanical shear forces of peristalsis. The important role of membrane-bound mucins at the apical cell surface and at the interface of the cell surface and the inner mucus layer was demonstrated by Mucl-deficient mice showing increased susceptibility to invasion by Campylobacter jejuni [44].

Intestinal Mucus Barrier, Microbes, and Probiotics

The human adult intestinal microbiota colonizing the outer loosely adherent mucus layer is made up of more than $10^{14}$ bacteria with increasing gradient of concentration and complexity of bacterial population from jejunum to colon; stomach, duodenum, and jejunum with $10^{2}-10^{3}$ aerobic bacteria per gram luminal content, and $10^{7}-10^{8}$ and $10^{11}$ $10^{12}$ predominantly anaerobic bacteria per gram in distal ileum and colon, respectively [45•]. Recent studies using 
Table 1 Thickness of the two mucus layers in vivo in the rat gastrointestinal tract ${ }^{\mathrm{a}}$

\begin{tabular}{|c|c|c|c|c|c|c|}
\hline \multirow[t]{3}{*}{ Mucus layer } & \multicolumn{6}{|c|}{ Mean mucus thickness $\pm \mathrm{SE}, \mu m$} \\
\hline & \multicolumn{2}{|l|}{ Stomach } & \multicolumn{3}{|c|}{ Small intestine } & \multirow{2}{*}{$\begin{array}{l}\text { Colon } \\
1-2 \mathrm{~cm} \text { distal to cecum }\end{array}$} \\
\hline & Corpus & Antrum & Duodenum & Jejunum & Ileum & \\
\hline Loosely adherent mucus layer & $109 \pm 12$ & $120 \pm 38$ & $154 \pm 39$ & $108 \pm 5$ & $447 \pm 47$ & $714 \pm 109$ \\
\hline Firmly adherent mucus layer & $80 \pm 5$ & $154 \pm 16$ & $16 \pm 3$ & $15 \pm 2$ & $29 \pm 8$ & $116 \pm 51$ \\
\hline Total mucus layer & $189 \pm 11$ & $274 \pm 41$ & $170 \pm 38$ & $123 \pm 4$ & $476 \pm 47$ & $830 \pm 110$ \\
\hline
\end{tabular}

${ }^{\text {a }} N=6-11$ animals per determination.

SE - standard error.

(Data from Atuma et al. [36].)

culture-independent techniques of $16 \mathrm{~S}$ ribosomal RNA gene sequencing and meta genomic sequencing methods estimate the presence of 200-300 species per individual from more than 1000 prevalent bacterial species in human adult intestine. It was further shown that $99 \%$ of intestinal resident/commensal microbiota belongs to only four phyla: Firmicutes (composed mostly of Clostridium XIX and IV groups) and Bacteroidetes (which together constitute more than $90 \%$ of the total intestinal microbes), with Proteobacteria and Actinobacteria making up the rest. However, the analysis of mucosally associated bacteria showed enrichment of streptococcal and Lactobacillus spp (Bacillus subgroup of Firmicutes) [46, 47].

The normal intestinal mucosal epithelium has tolerance to commensal microbiota because of its ability to distinguish commensal microbiota from pathogenic microorganisms by their molecular patterns, such as microbeassociated molecular patterns and pathogen-associated molecular patterns, through pattern recognition receptors (PRRs) such as cell surface Toll-like receptors (TLRs) and cytoplasmic nucleotide-binding oligomerization domain (NOD) proteins [48, 49]. These PRRs are thought to activate a common signaling pathway leading to the activation of NF- $\mathrm{KB}$ that stimulates the production of inflammatory cytokines and co-stimulatory molecules. However, the normal intestinal epithelial cells express low levels of TLR4 and TLR2 and are hyporesponsive to the stimuli caused by the respective ligands.

Intestinal commensal microbiota depends on mucus and undigested dietary carbohydrates for binding sites and energy source and affects intestinal epithelial functions, including those of goblet cells and mucus layers, by a "cross talk" feedback mechanism. Diverse oligosaccharides of mucin glycoproteins were evolved to promote symbiotic relationship with commensal bacteria and to evade pathogens $[1,2,42 \cdot \bullet]$. Microbiota and microbial products can modulate mucin synthesis and secretion, either by direct activation of diverse signaling cascades or through bioactive factors generated by epithelial and lamina propria cells. Enteric pathogens circumvent the protective function of mucus layer by developing motility, mucolytic activity, and other virulence factors, causing the degradation and penetration of mucus layers and subsequent attachment and invasion of epithelial cells. The bacteria that gain access to the intestinal mucosal cell surface adhere more frequently to the glycocalyx of the most luminal portion of the villi or upper crypt in the intestine. Most commensal and pathogenic bacteria attach to the intestinal mucosal cells through interaction of adhesins to the mucosal receptors, such as integrins, carcinoembryonic antigen-related cell adhesion molecules (CEACAM) or sialylated, galactosylated, or mannosylated glycoproteins or glycolipids. Probiotics such as Lactobacillus plantarium were reported to induce MUC2 and MUC3 mucins and inhibit the adherence of EPEC (enteropathogenic Escherichia coli), indicating that enhanced mucus layers and glycocalyx overlying the intestinal epithelium and the occupancy of the microbial binding sites by Lactobacillus spp provide protection against invasion by the pathogens $[50,51]$. Probiotics also cause qualitative alterations in intestinal mucins, preventing the pathogen binding.

\section{Other Goblet Cell Products}

\section{Intestinal Trefoil Factor}

The trefoil factor family comprises a group of small peptides $(6.5-12 \mathrm{kDa})$ with three intramolecular disulphide bonds, which is highly expressed in the mucus-producing cells of the gastrointestinal tract and plays a significant role in epithelial restitution (Table 2) [8,52]. TFF3/intestinal trefoil factor (ITF) is expressed and secreted by goblet cells in the intestine, whereas TFF1 and TFF2 are expressed and secreted by gastric surface foveolar cells and mucous neck cells/pyloric glands, respectively. TFF3 is the second most 
Table 2 Major goblet cell products

\begin{tabular}{|c|c|c|c|c|}
\hline Study & Name & Other names & Peptide & Functions \\
\hline $\begin{array}{l}\text { Lievin-Le Moal and Servin [1], } \\
\text { Hollingsworth and Swanson [3], } \\
\text { Andrianifahanana et al. [4], Gum } \\
\text { et al. [15] }\end{array}$ & MUC2 & $\begin{array}{l}\text { Goblet cell mucin } \\
\text { Secretory mucin }\end{array}$ & $\begin{array}{l}\text { Monomer } \\
(2.5 \mathrm{MDa}) \\
\text { Oigomer } \\
(100 \mathrm{MDa})\end{array}$ & $\begin{array}{l}\text { Major component of mucus layers (protective } \\
\text { barrier, lubrication, elimination). Binding } \\
\text { sites and nutrient sources of microbes. }\end{array}$ \\
\hline $\begin{array}{l}\text { Hattrup and Gendler [21], Ho et al. } \\
\text { [22], Luu et al. [23] }\end{array}$ & $\begin{array}{l}\text { MUC1/ } \\
\text { MUC3/ } \\
\text { MUC17 }\end{array}$ & $\begin{array}{l}\text { Membrane-bound } \\
\text { mucin }\end{array}$ & $\begin{array}{l}\text { Variable sizes } \\
200->2000 \\
\mathrm{kDa}\end{array}$ & $\begin{array}{l}\text { Cell surface protective barrier, extracellular } \\
\text { portions cleaved or shed and bioactive for } \\
\text { epithelial restitution }\end{array}$ \\
\hline $\begin{array}{l}\text { Taupin and Podolsky [8], Kjellev } \\
\text { [52] }\end{array}$ & TFF3 & $\begin{array}{l}\text { Intestinal trefoil } \\
\text { factor (ITF) }\end{array}$ & $\begin{array}{l}\text { Monomer } \\
(6.6 \mathrm{kDa}) \\
\text { Dimer }(13 \mathrm{kDa})\end{array}$ & $\begin{array}{l}\text { Epithelial restitution and wound healing. } \\
\text { Facilitates cell migration. Blocks apoptosis. } \\
\text { Increases mucus viscosity and structural } \\
\text { integrity of mucus layers. }\end{array}$ \\
\hline $\begin{array}{l}\text { Artis et al. [57], Nair et al. [58], } \\
\text { Hogan et al. [59], Herbert et al. } \\
\text { [60] }\end{array}$ & RELM $\beta$ & $\begin{array}{l}\text { Resistin-like molecule } \\
\beta, \text { F1ZZ2 }\end{array}$ & $\begin{array}{l}\text { Monomer } \\
(12.5 \mathrm{kDa}) \\
\text { Dimer }(25 \mathrm{kDa})\end{array}$ & $\begin{array}{l}\text { Upregulates MUC2 expression/secretion. } \\
\text { Induces goblet cell hyperplasia. Functions as } \\
\text { Th2 cytokine-induced immune-effector } \\
\text { molecule in resistance to intestinal nematode } \\
\text { infection. Inhibits chemotaxis of nematode by } \\
\text { direct binding to their chemosensory } \\
\text { apparatus. }\end{array}$ \\
\hline $\begin{array}{l}\text { Johansson et al. [37], Kobayashi et al. } \\
\text { [62] }\end{array}$ & Fcgbp & $\begin{array}{l}\mathrm{Fc}-\gamma \text { binding } \\
\text { protein } \\
\text { IgG Fc binding protein }\end{array}$ & $\begin{array}{l}\text { Full-length } \\
\text { protein } \\
(596 \mathrm{kDa})\end{array}$ & $\begin{array}{l}\text { Binds } 1 \mathrm{gG} \text { antibodies. Stabilization and } \\
\text { cross-linking of the MUC } 2 \text { mucin networks } \\
\text { of the inner firm mucus layer. }\end{array}$ \\
\hline
\end{tabular}

abundant goblet cell product present in the theca of mature goblet cells, and monomeric $(6.6 \mathrm{kDa})$ and dimeric (13 $\mathrm{kDa})$ forms of TFF3 can be found in vivo. In vitro and in vivo studies indicate that TFF3 facilitates not only intestinal epithelial restitution but also mucosal protection $[8,52]$. TFF3 and mucin together were more effective in protecting epithelial cells in vitro when compared with either one alone [53]. Mice overexpressing rat TTF3 in the intestine showed increased resistance to intestinal damage and ulceration, whereas TFF3-deficient mice were more susceptible to dextran sodium sulfate (DSS)-induced colitis. Furthermore, administration of recombinant TFF3 improved DSS-induced colitis by restoring the capacity for restitution $[8,52]$. The recent studies on the molecular mechanisms through which TFF3 promotes epithelial restitution indicate the involvement of multiple interactive mechanisms. TFF3 facilitates cell migration but not cell proliferation, unlike other motogenic molecules, such as transforming growth factor $\beta$ (TGF $\beta)$ or hepatocyte growth factor (HGF). In addition, TFF3 blocks apoptosis and contributes to the innate immune response mediated by the mucosal sensor systems for commensal microbiota, such as Toll-like receptor family members, TLR2 and TLR4 [54]. TLR2 stimulation induced TFF3 transcription via Ras/MEK/ MAPK and PI3K/Akt pathways but not MUC2 transcription in vivo in mice. TLR2-deficient mice showed a selective defect in TFF3 and TFF3 administration improved DSS-induced colitis by suppressing mucosal apoptosis [54]. Furthermore, TFF3 has been suggested to increase the viscosity of mucin by binding to the $\mathrm{vWF} \mathrm{C}$ domain of $M U C 2$, enhancing the structural integrity of the intestinal mucus barrier [55]. Recently, TFF3 was reported to form disulfide-linked heteromer with Fcgbp protein, which could interact with $M U C 2$ mucin in a covalent and non-covalent manner, contributing to the stability of mucin network in the mucus layer [56].

\section{Resistin-like Molecule $\beta$}

RELM $\beta$ belongs to a family of resistin-like cytokine molecules consisting of small, cysteine-rich secreted proteins. It contains $12.5-\mathrm{kDa}$ subunits that form disulfide-dependent dimeric units. RELM $\beta$ is produced by goblet cells in the intestine, with an increasing anterior to caudad gradient, and secreted into the intestinal lumen at high concentration as a homodimer (Table 2) [57]. RELM $\beta$ is highly induced in the intestinal goblet cell by colonization with normal enteric bacteria and in mouse models of gastrointestinal helminth infection and inflammatory bowel disease [58, 59]. RELM $\beta$ may have an immunoregulatory function. RELM $\beta$ induced by Th2-associated nematode infection had antiparasitic activity through IL-4 and IL-13 dependent mechanism [60]. Induction of Th2 cytokines, IL-4 and IL-13, caused expulsion of parasites such as Nocardia brasiliensis and Heligmosomoides hypogyrus from the intestinal lumen, by inducing RELM $\beta$, which functions not only as Th2 cytokine immune effector molecule but also as an inhibitor of chemotaxis of parasites, interfering with parasite nutrition 
by directly binding to the chemosensory components of the parasites. Induction of RELM $\beta$ was much more significant than Muc2 and TFF3 on Th2 immune stimulation [60]. Furthermore, RELM $\beta$ upregulates $M u c 2$ transcription and secretion, contributing to the mucosal barrier integrity. It showed a markedly preventive effect on trinitrobenzene sulfonic acid (TNBS) - induced colitis in mice [61]. RELM $\beta$-deficient mice showed reduced susceptibility to Tcell-independent DSS-induced colitis, but increased susceptibility to T-cell-dependent TNBS-induced colitis, indicating that RELM $\beta$ may trigger protective or proinflammatory effects, depending on the nature of the chemically induced colitis [59].

\section{Fc- $\gamma$ Binding Protein}

Fc- $\gamma$ binding protein (Fcgbp) is expressed in the mucus granule of goblet cells [62]. Fcgbp contains 13 vWF D domains and was reported to bind IgG antibodies through Fc part of IgGs. Recent proteomic analyses of the two mucus layers from the colon of mice and humans showed that $\mathrm{N}$ terminal parts of Fegbp was covalently attached to Muc2 mucin (Table 2) [37]. It was suggested that covalent attachment of Fegbp protein to MUC2 contributes to cross linking and stabilization of mucin network in the inner mucus layer [37].

\section{Goblet Cells and Mucins in Disease}

\section{Intestinal Infections}

In most intestinal infections, induction of goblet cells and mucin synthesis and secretion occur frequently during acute phase. However, chronic infection results in the depletion of goblet cells and quantitative and qualitative alteration in mucus layers due both to altered synthesis and secretion of mucins and to microbial glycosidases and proteases $[1,2$, 48]. Rapid and massive secretion of goblet cell mucus not only facilitates the expulsion of pathogens but also maintains the integrity of mucus protective layers. Intestinal parasitic infections cause profound changes in the goblet cells and mucins of the small intestine. Many experimental helminth infections such as Nippostrongylus brasiliensis and Trichinella spiralis have been shown to cause intestinal goblet cell hyperplasia and increased mucus secretion, mediated by Th2 immune responses (IL-13 and IL-4), contributing to increased intestinal mucosal protection and worm expulsion [48, 63]. Expulsion of the nematode, Trichuris muris, in resistant, susceptible, and $M u c 2$-deficient mouse strains showed that the increased Muc2 production, observed exclusively in resistant mice, correlated with worm expulsion, whereas worm expulsion from the intestine was significantly delayed in Muc2-deficient mice [64••]. In addition, the mucus barrier in resistant mice was less permeable than that of susceptible mice. These findings underscore the important innate defense function of mucins in enteric infection.

However, with sustained hypersecretion of stored mucins, depletion of goblet cells occurs, resulting in defective mucin synthesis and mucus barrier. In $N$. brasiliensis infection in rodents, goblet cell hyperplasia is accompanied by alteration of terminal sugar residues of goblet cell mucins, such as increased sialylation, which is mainly responsible not only for the expulsion of damaged worms but also for the prevention and attachment/migration of normal worms [65]. The pathogens have evolved mechanisms to invade the intestinal mucosal cells by penetrating through the mucus layers. A protozoan parasite, Entamoeba histolytica colonizes mucus layer of the colon by adhering to mucin oligosaccharides. The parasite then invades through the mucus layers by secreting cysteine proteases, which cleave the MUC2 mucin, resulting in defective mucus barriers, through which it can invade and attach to the intestinal mucosal cell surface [66].

\section{Cystic Fibrosis}

Despite the well-known clinical manifestation of mucus accumulation in the lung, intestine, and other organs in CF, the mechanisms underlying mucus-associated pathology remain unclear [67]. Within goblet cells, mature mucin polymers are thought to exist in a highly condensed form, due mainly to neutralization of the repulsive forces of the polyanionic charge of the oligosaccharide side chains by the high concentration of $\mathrm{H}^{+}$and $\mathrm{Ca}^{++}$within the granules. During exocytosis, $\mathrm{H}^{+}$and $\mathrm{Ca}^{++}$are removed from the anionic sites by extracellular $\mathrm{HCO}_{3}{ }^{-}$causing rapid expansion of compact mucin polymers into the meshed network of viscous mucus gels due to anionic repulsive electrostatic forces $\left[68,69{ }^{\circ}\right.$. The loss of CFTR in CF results in the loss of $\mathrm{Cl}^{-}$and $\mathrm{HCO}_{3}{ }^{-}$transport [69॰]. $\mathrm{HCO}_{3}^{-}$is critical for normal mucus gel formation, and aggregated mucus observed in CF may be caused by defective $\mathrm{HCO}_{3}{ }^{-}$transport $[67,69 \cdot]$. Increased fucosylation of mucin glycans due to induction of fucosyl $\alpha 1-2$ glycosyltransferase may also contribute to the increased viscosity of mucin [70]. CF mice exhibited decreased intestinal motility with longer exposure to the bacteria entrapped in the mucus and small intestinal bacterial overgrowth, which responded to treatment with antibiotics and laxatives [71].

\section{Inflammatory Bowel Disease}

IBD is thought to be caused by continuous pathologic immune responses to altered and/or dysbiosis of commensal 
microbes and microbial products [45, 72]. Accumulating evidence indicates that complex interactions of the following events are involved in the pathogenesis of IBD: 1) altered and/or dysbiosis of commensal microbiota, such as decreased ratio of protective to aggressive commensal bacterial species or functional alteration of commensal bacteria; 2) defective bacterial killing and processing by the intestinal mucosal cells due to genetic defect; 3 ) defective mucosal barrier function resulting from abnormal synthesis and or processing of mucins and TFF3; and 4) defective host immune response, such as defective innate and or adaptive immunity. Alterations of mucin production and glycosylation occur in IBD, but whether they contribute to initiation of inflammation or are the result of inflammation is unknown.

Goblet cells are reduced in number and size in ulcerative colitis. Recent studies in mouse models of colitis highlight the importance of the role of mucin in maintaining the integrity of protective mucus barriers whose breakdown can result in colitis. Muc2-deficient mice with no morphologically identifiable goblet cells and absent $M u c 2$ expression (TFF3 and RELM $\beta$ were expressed) in the intestine recently were reported to have markedly deficient mucus layers with increased permeability and enhanced bacterial adhesion to the mucosal cell surfaces. These mice developed spontaneous colitis and were susceptible to DSS-induced colitis [41, 43]. Two strains of mice with single missense mutations in oligomerization domains (vWF D3 and vWF C, respectively) showed aberrant $\mathrm{Muc} 2$ synthesis, reduced storage of mucin in the theca of goblet cells, diminished mucus layers with increased permeability and increased production of Th1 and Th2 cytokines, and developed spontaneous distal colitis and increased susceptibility to DSS-induced colitis [73••]. These mice showed aberrant assembly and processing of mucin complex and biochemical and histologic evidence of endoplasmic reticulum stress in goblet cells and Paneth cells, the phenomena observed in the patients with ulcerative colitis $[73 \bullet \bullet]$.

Changes in mucin glycosylation have been reported to cause defective mucus barrier and increased permeability and increased susceptibility to DSS-induced colitis, which may be caused by early thinning and weakening of the mucous layer allowing increased bacterial translocation [74]. Mice lacking core $3 \beta 1,3-N$-acetylgulcosaminyl-transferase enzyme with defective O-glycans in mucins showed decreased $\mathrm{Muc2}$ synthesis, increased intestinal permeability and increased susceptibility to DSS-induced colitis [75••]. Similarly, mice lacking core $2 \beta 1,6-N$-acetylglucosaminyl-transferase enzyme that initiate core 2 type protein $\mathrm{O}$ glycosylation in mucin, demonstrated increased intestinal permeability and increased susceptibility to DSS-induced colitis [76].

Increased numbers of mucosa-associated (adherent invasive) $E$. coli are observed in IBD. A recent study on tissue-associated microflora using 16S rRNA gene sequencing in patients with IBD showed that the IBD group had depletion of commensal bacteria, especially members of the phyla Firmicutes (largely Clostridium XIVa and IV groups) and Bacteroidetes with concomitant increases in Proteobacteria and Actinobacteria [46]. Although the causes of the altered pattern of microflora (dysbiosis) in IBD patients are not clear, a recent observation that coordinated regulation of glycan degradation and polysaccharide capsule synthesis can occur in the intestinal lumen, underscores the importance of the dynamic interplay between mucin glycan metabolism and microbial ecology $[42 \bullet \bullet]$.

\section{Mucinous Adenocarcinoma}

Mucinous carcinoma is characterized by pools of abundant amounts of extracellular mucin, and defined as the tumor with mucin representing more than $50 \%$ of the tumor mass. By contrast, signet-ring cell carcinoma is defined by the presence of more than $50 \%$ of tumor cells with prominent intracytoplasmic mucin, and has worse prognosis than mucinous carcinoma. Mucinous carcinoma occurs more frequently in the colon, where it accounts for $6-19 \%$ of all colorectal cancer cases, than in the small intestine, where it occurs mostly in the appendix. Mucinous carcinoma has clinicopathologic properties and molecular changes that are different from nonmucinous cancer, such as higher stage at diagnosis, more frequent invasion of adjacent organs, lymph node metastasis and peritoneal dissemination, and more frequent occurrence of microsatellite instability (MSI), CpG island methylator phenotype (CIMP), and BRAF mutations [77].

The changes in mucins that occur in colorectal cancer may be broadly classified into two main types: aberrant mucin gene regulation and glycosylation. Mucinous carcinoma expresses high levels of $M U C 2$ goblet cell mucin whereas $M U C 2$ expression is downregulated in nonmucinous cancer. Upregulation of $M U C 2$ transcription in mucinous carcinoma is caused by altered epigenetic and genetic regulation of $M U C 2$, such as $M U C 2$ promoter hypomethylation and increased binding of goblet cell lineage associated transcription factor, HATH1, to MUC2 promoter [13, 34]. Mucinous carcinoma ectopically expresses gastric mucin, MUC5AC, which is absent from normal intestine, more frequently than nonmucinous cancer. In addition, $M U C 1$ membrane mucin is expressed at lower level in mucinous carcinoma compared to nonmucinous cancer [78]. Changes in glycan structures of mucins in epithelial cancers include truncation of oligosaccharide side chains (resulting in the expression of $\mathrm{T}, \mathrm{Tn}$, sialylTn antigenic determinants) and neosynthesis of glycans (resulting in the expression of sialylLeA and sialylLeX antigens). Studies have shown that these glycan antigens are highly 
expressed in both mucinous and nonmucinous cancers [3, $4,25,79]$.

Accumulating evidence indicates that mucin plays an important role in several stages of metastatic processes of colorectal cancer. First, colon cancer cell lines selected for high capacity for metastasis express high levels of $M U C 2$. Second, colon cancer cells selected for high mucin production showed increased liver colonization and metastasis. Third, inhibition of mucin O-glycosylation in colon cancer cells decreased cancer cell binding to E-selectin expressed on endothelial cells, and liver colonization. Fourth, downregulation of $M U C 2$ expression by antisense techniques decreases the metastatic activity of human colon cancer cells in nude mouse model system. To summarize, altered level and pattern of mucin gene expression and altered glycosylation in cancer cells affect their biologic properties, such as cell proliferation, adhesion, motility, invasion, escape from host immune surveillance, tumorigenicity, and metastasis [79].

\section{Conclusions}

The major function of intestinal goblet cells and their main secretory product, mucin, is the formation of mucus layers which serve as the front line innate host defense mechanism. The mucus layers play key roles in the establishment of the commensal intestinal microbiota and the protection from colonization and invasion by the pathogenic microbiota. The defective mucosal barrier, abnormal commensal bacteria, and defective host innate and adaptive immune response result in intestinal inflammation and injury. Identification of the specific epitopes in mucin glycoproteins as binding sites for commensal and pathogenic microbes in health and disease, and analysis of the effect of native and altered mucins on the ratio of protective/ aggressive commensal microbes in the intestine, will contribute significantly to the development of novel therapeutic approaches in the management of intestinal diseases. Methods to promote or strengthen the intestinal mucus layer or the content of bioactive protective molecules may also be helpful in prevention or therapy of intestinal diseases. Further studies are needed on identification and functional significance of various components of mucus layers and the complex interactions between mucus layers, microbiota (prebiotics and probiotics), epithelial cells, and the underlying innate and adaptive immunity. In addition to the formation of a protective barrier, mucins play an important role in the development and progression of cancer. Changes in mucins caused by altered mucin gene regulation and/or altered mucin glycosylation in cancer cells serve not only as diagnostic and prognostic tumor markers but also as therapeutic targets. Further elucidation of the regulatory mechanisms involved in mucin changes in cancer and inflammation will be important for the development of novel therapeutic approaches.

Acknowledgments This work was supported by the Research Service, Department of Veterans Affairs, and National Institutes of Health center grant DK080506 (SBH). The authors thank Dr. Gunnar Hannson for critically reviewing the manuscript.

Disclosure No potential conflict of interest relevant to this article was reported.

Open Access This article is distributed under the terms of the Creative Commons Attribution Noncommercial License which permits any noncommercial use, distribution, and reproduction in any medium, provided the original author(s) and source are credited.

\section{References}

Papers of particular interest, published recently, have been highlighted as:

- Of importance

•- Of major importance

1. Lievin-Le Moal V, Servin AL: The front line of enteric host defense against unwelcome intrusion of harmful microorganisms: mucins, antimicrobial peptides, and microbiota. Clin Microbiol Rev 2006, 19:315-337.

2. - Dharmani P, Srivastava V, Kissoon-Singh V, et al.: Role of intestinal mucins in innate host defense mechanisms against pathogens. J Innate Immun 2009, 1:123-135. This article provides a succinct review of the role of mucin in innate host defense against commensal and pathogenic microbiota and the role of intestinal microbes in mucin regulation.

3. Hollingsworth MA, Swanson BJ: Mucins in cancer: protection and control of the cell surface. Nat Rev Cancer 2004, 4:45-60.

4. Andrianifahanana M, Moniaux N, Batra SK: Regulation of mucin expression: mechanistic aspects and implications for cancer and inflammatory diseases. Biochim Biophys Acta 2006, 1765:189-222.

5. - McGuckin MA, Eri R, Simms LA, et al.: Intestinal barrier dysfunction in inflammatory bowel diseases. Inflamm Bowel Dis 2009, 15:100-113. This article provides a critical review of the components of the secreted and cellular barrier and their regulation and the evidence of barrier dysfunction in $I B D$.

6. - van der Flier LG, Clevers H: Stem cells, self-renewal, and differentiation in the intestinal epithelium. Annu Rev Physiol 2009, 71:241-260. This article provides a succinct summary of the current view of intestinal stem cells and genetic hierarchy responsible for cell fate commitment and differentiation in normal and diseased intestine.

7. Velcich A, Yang W, Heyer J, et al.: Colorectal cancer in mice genetically deficient in the mucin Muc2. Science 2002, 295:17261729.

8. Taupin D, Podolsky DK: Trefoil factors: initiators of mucosal healing. Nat Rev Mol Cell Biol 2003, 4:721-732.

9. Karam SM: Lineage commitment and maturation of epithelial cells in the gut. Front Biosci 1999, 4:D286-298. 
10. Deplancke B, Gaskins HR: Microbial modulation of innate defense: goblet cells and the intestinal mucus layer. Am J Clin Nutr 2001, 73:1131S-1141S.

11. Stanger BZ, Datar R, Murtaugh LC, et al.: Direct regulation of intestinal fate by Notch. Proc Natl Acad Sci U S A 2005, 102:1244312448.

12. Yang Q, Bermingham NA, Finegold MJ, et al.: Requirement of Math1 for secretory cell lineage commitment in the mouse intestine. Science 2001, 294:2155-2158.

13. Park ET, Oh HK, Gum JR, Jr, et al.: HATH1 expression in mucinous cancers of the colorectum and related lesions. Clin Cancer Res 2006, 12:5403-5410.

14. Davis CW, Dickey BF: Regulated airway goblet cell mucin secretion. Annu Rev Physiol 2008, 70:487-512.

15. Gum JR, Byrd JC, Hicks JW, et al.: Molecular cloning of human intestinal mucin cDNAs. Sequence analysis and evidence for genetic polymorphism. J Biol Chem 1989, 264:6480-6487.

16. Gum JR Jr, Hicks JW, Toribara NW, et al.: Molecular cloning of human intestinal mucin (MUC2) cDNA. Identification of the amino terminus and overall sequence similarity to prepro-von Willebrand factor. J Biol Chem 1994, 269:2440-2446.

17. Godl K, Johansson ME, Lidell ME, et al.: The $\mathrm{N}$ terminus of the MUC2 mucin forms trimers that are held together within a trypsin-resistant core fragment. J Biol Chem 2002, 277:4724847256.

18. Lidell ME, Johansson ME, Morgelin M, et al.: The recombinant C-terminus of the human MUC2 mucin forms dimers in Chinesehamster ovary cells and heterodimers with full-length MUC2 in LS 174T cells. Biochem J 2003, 372:335-345.

19. Gum JR Jr, Ho JJ, Pratt WS, et al.: MUC3 human intestinal mucin. Analysis of gene structure, the carboxyl terminus, and a novel upstream repetitive region. J Biol Chem 1997, 272:2667826686.

20. Gum JR Jr, Hicks JW, Crawley SC, et al.: Initiation of transcription of the MUC3A human intestinal mucin from a TATA-less promoter and comparison with the MUC3B amino terminus. J Biol Chem 2003, 278:49600-49609.

21. Hattrup CL, Gendler SJ: Structure and function of the cell surface (tethered) mucins. Annu Rev Physiol 2008, 70:431-457.

22. Ho SB, Dvorak LA, Moor RE, et al.: Cysteine-rich domains of muc3 intestinal mucin promote cell migration, inhibit apoptosis, and accelerate wound healing. Gastroenterology 2006, 131:15011517.

23. Luu Y, Junker W, Rachagani S, et al.: Human intestinal MUC17 mucin augments intestinal cell restitution and enhances healing of experimental colitis. Int J Biochem Cell Biol 2010, 42:996-1006.

24. Carlstedt I, Sheehan JK: Structure and macromolecular properties of cervical mucus glycoproteins. Symp Soc Exp Biol 1989, 43:289-316.

25. Kim YS, Deng G: Aberrant expression of carbohydrate antigens in cancer: the role of genetic and epigenetic regulation. Gastroenterology 2008, 135:305-309.

26. - Brockhausen I, Schacter H, Stanley P: O-GalNAc glycans. In Essentials of Glycobiology. Edited by Varki A, Cummings RD, Esko JD. Woodbury, NY: Cold Spring Harbor Laboratory Press; 2009:115-127. This is a concise review of the structure, biosynthesis, and function of mucin O-glycans.

27. Theodoropoulos G, Carraway KL: Molecular signaling in the regulation of mucins. J Cell Biochem 2007, 102:1103-1116.

28. Thai P, Loukoianov A, Wachi S, et al.: Regulation of airway mucin gene expression. Annu Rev Physiol 2008, 70:405-429.

29. Li J-D, Feng W, Gallup M, et al.: Activation of NF-kB via a Src-dependent Ras-MAPK-pp90rsk pathway is required for Pseudomonas aeruginosa-induced mucin overproduction in epithelial cells. Proc Natl Acad Sci U S A 1998, 95:57185723.
30. Ahn DH, Crawley SC, Hokari R, et al.: TNF-alpha activates MUC2 transcription via NF-kappaB but inhibits via JNK activation. Cell Physiol Biochem 2005, 15:29-40.

31. Iwashita J, Sato $Y$, Sugaya $H$, et al.: mRNA of MUC2 is stimulated by IL-4, IL-13 or TNF-alpha through a mitogenactivated protein kinase pathway in human colon cancer cells. Immunol Cell Biol 2003, 81:275-282.

32. Hokari R, Lee H, Crawley SC, et al.: Vasoactive intestinal peptide upregulates MUC2 intestinal mucin via CREB/ATF1. Am J Physiol Gastrointest Liver Physiol 2005, 289:G949-959.

33. Gregorieff A, Stange DE, Kujala P, et al.: The ets-domain transcription factor Spdef promotes maturation of goblet and Paneth cells in the intestinal epithelium. Gastroenterology 2009, 137:1333-1345 e1331-1333.

34. Okudaira K, Kakar S, Cun L, et al.: MUC2 gene promoter methylation in mucinous and non-mucinous colorectal cancer tissues. Int J Oncol 2010, 36:765-775.

35. Yamada N, Hamada T, Goto M, et al.: MUC2 expression is regulated by histone $\mathrm{H} 3$ modification and DNA methylation in pancreatic cancer. Int J Cancer 2006, 119:1850-1857.

36. Atuma C, Strugala V, Allen A, et al.: The adherent gastrointestinal mucus gel layer: thickness and physical state in vivo. Am J Physiol Gastrointest Liver Physiol 2001, 280:G922-G929.

37. Johansson ME, Thomsson KA, Hansson GC: Proteomic analyses of the two mucus layers of the colon barrier reveal that their main component, the Muc2 mucin, is strongly bound to the Fcgbp protein. J Proteome Res 2009, 8:3549-3557.

38. Ho SB, Takamura K, Anway R, et al.: The adherent gastric mucous layer is composed of alternating layers of MUC5AC and MUC6 mucin proteins. Dig Dis Sci 2004, 49:1598-1606.

39. Phillipson M, Johansson ME, Henriksnas J, et al.: The gastric mucus layers: constituents and regulation of accumulation. Am J Physiol Gastrointest Liver Physiol 2008, 295:G806-G812.

40. Didierlaurent A, Sirard JC, Kraehenbuhl JP, et al.: How the gut senses its content. Cell Microbiol 2002, 4:61-72.

41. •- Johansson ME, Phillipson M, Petersson J, et al.: The inner of the two Muc2 mucin-dependent mucus layers in colon is devoid of bacteria. Proc Natl Acad Sci U S A 2008, 105:15064-15069. This article provides definitive evidences for the presence, identity, and differential microbial association of two mucus layers in mouse colon and for the defective mucus barrier, increased permeability, and susceptibility to experimental colitis in Muc2deficient mice.

42. •• Martens EC, Roth R, Heuser JE, et al.: Coordinate regulation of glycan degradation and polysaccharide capsule biosynthesis by a prominent human gut symbiont. J Biol Chem 2009, 284:1844518457. This article describes a novel regulatory pathway involving O-glycan targeting outer membrane protein on a gut bacterium that governs the coordinated regulation of O-glycan catabolism and capsule synthesis.

43. Van der Sluis M, De Koning BA, De Bruijn AC, et al.: Muc2deficient mice spontaneously develop colitis, indicating that MUC2 is critical for colonic protection. Gastroenterology 2006, 131:117-129.

44. McAuley JL, Linden SK, Png CW, et al.: MUC1 cell surface mucin is a critical element of the mucosal barrier to infection. $\mathrm{J}$ Clin Invest 2007, 117:2313-2324.

45. - Sartor RB: Microbial influences in inflammatory bowel diseases. Gastroenterology 2008, 134:577-594. This is a comprehensive review on intestinal commensal and pathogenic microbiota/host interactions in health and disease and in rodent models of IBD.

46. Frank DN, St Amand AL, Feldman RA, et al.: Molecularphylogenetic characterization of microbial community imbalances in human inflammatory bowel diseases. Proc Natl Acad Sci U S A 2007, 104:13780-13785. 
47. Qin J, Li R, Raes J, et al.: A human gut microbial gene catalogue established by metagenomic sequencing. Nature 2010, 464:59-65.

48. Moncada DM, Kammanadiminti SJ, Chadee K: Mucin and Tolllike receptors in host defense against intestinal parasites. Trends Parasitol 2003, 19:305-311.

49. Fukata M, Abreu MT: Pathogen recognition receptors, cancer and inflammation in the gut. Curr Opin Pharmacol 2009, 9:680 687.

50. Mack DR, Michail S, Wei S, et al.: Probiotics inhibit enteropathogenic E. coli adherence in vitro by inducing intestinal mucin gene expression. Am J Physiol 1999, 276:G941-G950.

51. Sherman PM, Ossa JC, Johnson-Henry K: Unraveling mechanisms of action of probiotics. Nutr Clin Pract 2009, 24:10-14.

52. Kjellev S: The trefoil factor family - small peptides with multiple functionalities. Cell Mol Life Sci 2009, 66:1350-1369.

53. Kindon H, Pothoulakis C, Thim L, et al.: Trefoil peptide protection of intestinal epithelial barrier function: Cooperative interaction with mucin glycoprotein. Gastroenterology 1995, 109:516-523.

54. Podolsky DK, Gerken G, Eyking A, et al.: Colitis-associated variant of TLR2 causes impaired mucosal repair because of TFF3 deficiency. Gastroenterology 2009, 137:209-220.

55. Tomasetto C, Masson R, Linares J-S, et al.: pS2/TFF1 interacts directly with the VWFC cysteine-rich domains of mucins. Gastroenterology 2000, 118:70-80.

56. Albert TK, Laubinger W, Müller S, et al.: Human intestinal TFF3 forms disulfide-linked heteromers with the mucus-associated FCGBP protein and is released by hydrogen sulfide. J Proteome Res 2010 (Epub ahead of print).

57. Artis D, Wang ML, Keilbaugh SA, et al.: RELMbeta/FIZZ2 is a goblet cell-specific immune-effector molecule in the gastrointestinal tract. Proc Natl Acad Sci U S A 2004, 101:13596-13600.

58. Nair MG, Guild KJ, Du Y, et al.: Goblet cell-derived resistin-like molecule beta augments CD4+ T cell production of IFN-gamma and infection-induced intestinal inflammation. J Immunol 2008, 181:4709-4715.

59. Hogan SP, Seidu L, Blanchard C, et al.: Resistin-like molecule beta regulates innate colonic function: barrier integrity and inflammation susceptibility. J Allergy Clin Immunol 2006, 118:257-268.

60. Herbert DR, Yang JQ, Hogan SP, et al.: Intestinal epithelial cell secretion of RELM-beta protects against gastrointestinal worm infection. J Exp Med 2009, 206:2947-2957.

61. Krimi RB, Kotelevets L, Dubuquoy L, et al.: Resistin-like molecule beta regulates intestinal mucous secretion and curtails TNBS-induced colitis in mice. Inflamm Bowel Dis 2008, 14:931941.

62. Kobayashi K, Ogata H, Morikawa M, et al.: Distribution and partial characterisation of IgG Fc binding protein in various mucin producing cells and body fluids. Gut 2002, 51:169-176.

63. Knight PA, Brown JK, Pemberton AD: Innate immune response mechanisms in the intestinal epithelium: potential roles for mast cells and goblet cells in the expulsion of adult Trichinella spiralis. Parasitology 2008, 135:655-670.

64. •- Hasnain SZ, Wang H, Ghia JE, et al.: Mucin gene deficiency in mice impairs host resistance to an enteric parasitic infection. Gastroenterology 2010, 138:1763-1771. This recent study shows that mucin is an important component of innate defense in nematode infection in resistant, susceptible, and Muc2-deficient mice.

65. Ishikawa N, Horii Y, Oinuma T, et al.: Goblet cell mucins as the selective barrier for the intestinal helminths: T-cell-independent alteration of goblet cell mucins by immunologically 'damaged'
Nippostrongylus brasiliensis worms and its significance on the challenge infection with homologous and heterologous parasites. Immunology 1994, 81:480-486.

66. Lidell ME, Moncada DM, Chadee K, et al.: Entamoeba histolytica cysteine proteases cleave the MUC2 mucin in its C-terminal domain and dissolve the protective colonic mucus gel. Proc Natl Acad Sci U S A 2006, 103:9298-9303.

67. O'Sullivan BP, Freedman SD: Cystic fibrosis. Lancet 2009, 373:1891-1904.

68. Chin WC, Quesada I, Nguyen T, et al.: Oscillations of $\mathrm{pH}$ inside the secretory granule control the gain of $\mathrm{Ca}_{2}^{+}$release for signal transduction in goblet cell exocytosis. Novartis Found Symp 2002, 248:132-141; discussion 141-139, 277-182.

69. - Garcia MA, Yang N, Quinton PM: Normal mouse intestinal mucus release requires cystic fibrosis transmembrane regulatordependent bicarbonate secretion. J Clin Invest 2009, 119:26132622. This recent study provides evidence indicating that defective CFTR dependent-HCO3- secretion causes aggregated mucus in various organs in CF mice.

70. Thomsson KA, Hinojosa-Kurtzberg M, Axelsson KA, et al.: Intestinal mucins from cystic fibrosis mice show increased fucosylation due to an induced Fucalpha1-2 glycosyltransferase. Biochem J 2002, 367:609-616.

71. De Lisle RC, Roach E, Jansson K: Effects of laxative and Nacetylcysteine on mucus accumulation, bacterial load, transit, and inflammation in the cystic fibrosis mouse small intestine. Am J Physiol Gastrointest Liver Physiol 2007, 293:G577G584.

72. Xavier RJ, Podolsky DK: Unravelling the pathogenesis of inflammatory bowel disease. Nature 2007, 448:427-434.

73. •- Heazlewood CK, Cook MC, Eri R, et al.: Aberrant mucin assembly in mice causes endoplasmic reticulum stress and spontaneous inflammation resembling ulcerative colitis. PLoS Med 2008, 5:e54. This report provides important evidence indicating that mucin misfolding can cause endoplasmic reticulum stress and can be a primary cause for pathogenesis of colitis.

74. Johansson MEV, Gustafsson JK, Sjöberg KE, et al.: Bacteria penetrate the inner mucus layer before inflammation in the dextran sulfate colitis model. PloS One 2010, in press.

75. •- An G, Wei B, Xia B, et al.: Increased susceptibility to colitis and colorectal tumors in mice lacking core 3-derived O-glycans. J Exp Med 2007, 204:1417-1429. This is the first report describing the causal relationship between defective O-glycan synthesis and reduced Muc2 protein, defective intestinal barrier, and increased susceptibility to experimental colitis in mice.

76. Stone EL, Ismail MN, Lee SH, et al.: Glycosyltransferase function in core 2-type protein O glycosylation. Mol Cell Biol 2009, 29:3770-3782.

77. Tanaka H, Deng G, Matsuzaki K, et al.: BRAF mutation, $\mathrm{CpG}$ island methylator phenotype and microsatellite instability occur more frequently and concordantly in mucinous than non-mucinous colorectal cancer. Int J Cancer 2006, 118:27652771.

78. Kim DH, Kim JW, Cho JH, et al.: Expression of mucin core proteins, trefoil factors, APC and p21 in subsets of colorectal polyps and cancers suggests a distinct pathway of pathogenesis of mucinous carcinoma of the colorectum. Int J Oncol 2005, 27:957964.

79. Byrd JC, Bresalier RS: Mucins and mucin binding proteins in colorectal cancer. Cancer Metastasis Rev 2004, 23:77-99. 